\title{
Justicia después de la guerra
}

Jens David Ohlin*

J.D., Columbia Law School. Ph.D., Columbia University. Profesor, School of Law, Cornell University, Nueva York, EE.UU.

Correo electrónico: jdo43@cornell.edu

Cómo citar este artículo: Jens David Ohlin. Justicia después de la guerra. Trad. William E. Ulrich. DIXI 24. Octubre 2016. Pág. 143. doi: http://dx.doi.org/10.16925/di.v18i24.1528

\section{Resumen}

Concluidas las hostilidades, ya sean o no conflictos armados formales, las partes deben rendir cuentas por su proceder. Este sentimiento es casi universalmente compartido, independientemente de la propia estructura moral o ética que tengan, aunque los detalles de esta responsabilidad son profundamente controversiales y discutidos. En la segunda sección de este breve artículo se ofrece una base normativa para la justicia después de la guerra que apela a la norma contra la impunidad. Se concluye que los procesos penales, en oposición a los mecanismos no penales, reivindican mejor la norma contra la impunidad. A la luz de esta conclusión, la tercera sección se hace las siguientes preguntas: ¿cómo debemos alcanzar la justicia después de la guerra? ¿Quién debe ser llevado a juicio, líderes o soldados de infantería? ¿En qué instancias deben juzgarlos: en los tribunales nacionales o en los internacionales? ¿Qué delitos se deben imputar: delitos de tipo nacional o crímenes internacionales? ¿Qué procedimientos deben seguirse en los juicios y cómo? Y ¿por qué deben ser castigados?

Palabras clave: castigo, derecho penal internacional, impunidad, jus post bellum, norma antiimpunidad, procedimiento penal internacional. 


\title{
Post-War Justice
}

\begin{abstract}
When hostilities reach a conclusion - whether or not they were part of a formal armed conflict-, the parties must be held accountable for their actions. This belief is almost universally held, regardless of one's moral or ethical convictions. However, the details of this responsibility are highly controversial and disputed. In the second section of this short article, a legal basis for post-war justice is provided that appeals to the anti-impunity norm. It is then concluded that criminal proceedings uphold the anti-impunity norm better than non-criminal mechanisms. In light of this conclusion, the third section poses the following questions: How do we achieve post-war justice? Who should be brought to trial: leaders or soldiers? Should they be tried in national or international courts? What should they be charged with: national or international crimes? What procedures should be followed in the trials and how? Finally, why should they be punished?
\end{abstract}

Keywords: punishment, international criminal law, impunity, jus post bellum, anti-impunity norm, international criminal procedure

\section{Justiça depois da guerra}

\section{Resumo}

Concluídas as hostilidades, sendo ou não conflitos armados formais, as partes devem prestar contas pelas suas ações. Esse sentimento é quase universalmente compartilhado, independentemente da própria estrutura moral ou ética que tiverem, embora os detalhes dessa responsabilidade sejam profundamente controversos e discutidos. Na segunda seção deste breve artigo, sugere-se uma base normativa para a justiça depois da guerra que apela para a norma contra a impunidade. Conclui-se que os processos penais, em oposição aos mecanismos não penais, reivindicam melhor a norma contra a impunidade. À luz dessa conclusão, a terceira seção faz as seguintes perguntas: como devemos alcançar a justiça depois da guerra? Quem deve ser levado a julgamento, líderes ou soldados de infantaria? Em que instâncias devem ser julgados: nos tribunais nacionais ou nos internacionais? Que delitos devem imputar: delitos de tipo nacional ou crimes internacionais? Que procedimentos devem ser seguidos nos tribunais e como? E por que devem ser condenados?

Palavras-chave: condenação, direito penal internacional, impunidade, jus post bellum, norma anti-impunidade, procedimento penal internacional. 


\section{INTRODUCCIÓN ${ }^{1}$}

Concluidas las hostilidades, ya sea de un conflicto armado formal o no formal, ambos bandos están llamados a responder por su comportamiento. Este sentimiento es universalmente compartido, independientemente del punto de vista moral o ético, aunque los detalles de este tema sean profundamente controversiales y discutidos. En la segunda parte de este artículo ofrezco una base normativa para la justicia después de la guerra, la cual hace alusión a la regla de no impunidad, y concluyo que los juicios penales en oposición a los mecanismos no penales justifican mejor esta norma. De acuerdo con esta conclusión, en la tercera parte se formulan las siguientes preguntas: ¿Cómo debemos alcanzar la justicia después de la guerra? ¿Quiénes deben ser llevados a los estrados judiciales, los líderes o sus subalternos? ¿Quién debe enjuiciarlos, las cortes nacionales o internacionales)? ¿Cuáles delitos deben serles imputados, delitos de naturaleza nacional o internacional? ¿Qué procedimiento debe regir dentro de los procesos? ¿Cómo llevar a cabo estos procesos? Y, ¿por qué ellos deben ser castigados?

\section{II. ¿POR QUÉ DEBE IMPORTARNOS LA JUSTICIA DESPUÉS DE LA GUERRA?}

La base moral para la justicia de un posconflicto es la regla de la no impunidad que establece que esta es moralmente desastrosa y los mecanismos institucionales deben ser diseñados, junto con otros criterios, para evitar dicha impunidad tanto como sea posible. No obstante esta regla estar protegida por parámetros instrumentales (consecuencialismo), sostengo que un margen deontológico proporciona una base más convincente para la regla, aunque sea necesaria

El presente artículo se publicó originalmente en inglés por Oxford University Press en Oxford Handbook of the Ethics of War, Cornell Legal Studies Research Paper 15-04. La referencia específica es: Jens David Ohlin. Justice AFTER WAR November 29, 2014. Ed. By Helen Frowe y Seth Lazar Oxford Handbook of the Ethics of War. Oxford University Press. Véase Cornell Legal Studies Research Paper N. ${ }^{\circ}$ 15-04. Disponible en SSRN: http://ssrn.com/abstract=2531963. Traductor al español de este artículo: William E. Ulrich, docente de tiempo completo, Facultad de Derecho, Universidad Cooperativa de Colombia, sede Popayán, Colombia. Correo electrónico: william.ulricha@campusucc.edu.co una calibración más cuidadosa para el contexto internacional ${ }^{2}$.

$\mathrm{El}$ argumento instrumental afirma que la impunidad frente a las malas conductas durante una guerra traerá consigo futuras malas conductas: aquellos que cometen atrocidades y escapan esa mala conducta serán propensos a repetirla, y los terceros que son testigos a la impunidad estarán envalentonados a la hora de decidir si ellos cumplirán con las leyes de la guerra. Ahora bien, una investigación exhaustiva y los castigos a las malas conductas durante la guerra disuadirán a aquellos que hayan cometido infracciones de abstenerse de repetirlas, así como a los potenciales infractores de participar de estas conductas en un futuro. El argumento a priori es profundamente intuitivo pero muy complicado de construir: el castigo para las malas conductas en el tiempo de guerra está bien a priori, sin importar las consecuencias, simplemente porque la impunidad por estas conductas ofende al entramado moral del universo. La tensión entre las justificaciones instrumentalistas y deontológicas para los castigos internacionales es tan complicada como los problemas internos o nacionales con la normativa en los tiempos de paz. Si bien el contexto internacional muestra algunas particularidades que no se encuentran en un contexto nacional o interno, existe una afirmación plausible según la cual los infractores en potencia de la normativa criminal nacional o interna serán disuadidos —en algunas circunstancias muy limitadas - por la posibilidad de un castigo en el futuro. De igual forma, es mucho menos probable en el contexto de una guerra - donde la toma de decisiones muchas veces es inmune al proceso racional y lleva a abstenerse de actuar de forma más sencilla- que los genocidas o personas que han cometido crímenes contra la humanidad actúen por razones racionales, y a quienes las normas quizás no puedan disuadir con un sistema de recompensas y castigos $^{3}$. Aun cuando esto pueda ser real en un contexto nacional o interno, la falta de control durante una guerra, combinado con la intención genocida, hace que el problema de la disuasión sea especialmente urgente en el contexto internacional. Lo anterior permite que la justificación deontológica para un castigo sea más atractiva en el contexto de una guerra

\footnotetext{
2 Para un debate sobre la regla anti impunidad, véase Max Pensky. Amnesty on trial: Impunity, accountability and the norms of international law. Eтнics \& Global Politics 1. 2008. Pág. 40

3 Véase David Wippman. Atrocities, deterrence, and limits of international justice. FordHAM INTERNATIONAL LAW JOURNAL 23. 1999. Pág. 473. Véase también Julian Ku y Nzelibe. Do criminal tribunals deter or exacerbate humanitarian atrocities? WASHINGTON UNIVERSITY LAW QUARTERLY 84. 2007.
} 
en comparación con el ámbito interno o nacional. Esto produce una potencial asimetría entre los dos contextos, ya que es por lo menos conceptualmente posible apoyar una justificación utilitarista bajo uno de los entendidos, pero también es posible apoyar una justificación deontológica por el otro lado.

La verdadera pregunta es cómo aterrizar la regla antiimpunidad. Apoyo un acercamiento a dos niveles de los cimientos filosóficos para la justicia después de la guerra. Al nivel de responsabilidad individual por la conducta durante la guerra, un amplio margen retributivo se sostiene: aquellos que han obrado mal deben ser castigados simplemente porque se lo merecen y porque así se hace justicia a la regla del Derecho, de modo que al final de la guerra tendrá un valor a priori. Sin embargo, existe la tentación de enfocarse en cálculos consecuencialistas a un nivel global, lo cual conlleve a una respuesta penal a nivel individual que puede incentivar a grupos de víctimas a atacar buscando represalias, y dejar que sus quejas se queden en aquella regla del Derecho. Estas consideraciones consecuencialistas a un nivel global son muy importantes para el Derecho positivo, ya que muchas instituciones internacionales están motivadas a actuar cuando sus acciones ayudan a restaurar la paz y la seguridad internacional, pero las aspiraciones consecuencialistas deben ser atemperadas. La comunidad internacional debe evitar poner cargas demasiado grandes a los tribunales internacionales, los cuales deben concentrar sus esfuerzos en implementar el retribucionismo a un nivel individual ${ }^{4}$. Los peligros acechan cuando los tribunales y los fiscales se alejan del retribucionismo y toman decisiones basadas en consideraciones de seguridad colectiva, una tentación que deben resistir.

Existen dos caminos de compensación judicial para conductas ilegales durante un conflicto armado: mecanismos penales y no penales. Estos acercamientos ofrecen resultados muy diversos, y además fluyen desde diferentes bases filosóficas teniendo en cuenta el propósito y naturaleza de la justicia de un posconflicto. Aunque hay costos muy considerables ligados a los mecanismos penales, arguyo aquí que un acercamiento desde la ley penal reivindica mejor la regla antiimpunidad y logra justicia después de una guerra.

Algunos Estados enfrentados con las atrocidades del posconflicto han optado por mecanismos no penales para atender los requerimientos de la justicia

4 Véase Shahram Dana. The limits of judicial idealism: should the international criminal court engage consequentialist aspirations? Penn state journal of LaW \& international Affairs 3. 2014. Pág. 30 transicional, aunque una discusión a fondo de estos mecanismos alternativos sería poco práctica en este momento. Las observaciones que a continuación se hacen están garantizadas. Primero, aun cuando los mecanismos alternativos de justicia transicional no necesariamente resulten en castigos para los actores, dichos mecanismos pueden ser mejores a fin de establecer un archivo histórico de las conductas. Por ejemplo, el gobierno sudafricano creó su comisión de la verdad y la reconciliación con el objetivo de darle a los actores del conflicto un incentivo por su entrega de información de forma voluntaria. Cuando esto se canaliza hacia un proceso penal, los acusados tienen pocos incentivos para revelar información acerca de las actividades que los incriminan. De manera que visto a la luz del proceso penal, se puede afectar la construcción de ese archivo histórico, mientras un mecanismo alternativo no penal - más enfocado en la revelación de información y no en un mecanismo punitivo- producirá información más comprensiva.

Segundo, defensores de los mecanismos no penales ocasionalmente argumentan que insistir en castigos de tipo penales puede ser contraproducente para el objetivo de restaurar la paz y la seguridad de una región. Más concretamente, las organizaciones locales, ya sea a través de políticos de alto nivel o con las tropas en el área, pueden llegar a ser necesarios para incentivar a los beligerantes a dejar las armas y firmar un acuerdo de paz, y sin embargo, si las organizaciones son desfavorecidas en las leyes penales (los tribunales internacionales se niegan a reconocerlas como un asunto legal), esto puede llegar a ser una barrera para la resolución pacífica de un conflicto que se ha tornado demasiado violento ${ }^{5}$. El resultado es que algunos criminales continuarán la lucha en vez de negociar un acuerdo que resultaría en un juicio en su contra en las cortes internacionales. Así, la ley penal es muchas veces una barrera para alcanzar el objetivo consecuencialista de mejorar el cumplimiento de los derechos humanos en la zona.

Tercero, los mecanismos no penales pueden llegar a ser más recomendables para promover la paz y la reconciliación. En este sentido, el perdón es un elemento clave de un proyecto de justicia transicional, ya que un proceso puede verse frustrado por la naturaleza crecientemente retributiva de los procesos penales. En contraposición a lo anterior, una comisión de la verdad y la reconciliación puede motivar a las víctimas a perdonar a los agresores unas vez estos se hagan presentes ante la comisión y confiesen sus delitos. Los agresores pueden ir más allá y pedir

Véase el Estatuto de Roma, Artículo 27. 
perdón de forma directa (lo cual no está estrictamente dentro de un proceso), pero solo si están por fuera de un proceso penal, ya que las expresiones de culpa o remordimiento pueden traer consigo imputaciones y castigos.

Aunque los que abogan por los mecanismos no penales frecuentemente citan la experiencia de Sudáfrica, esta no puede ser generalizada. Si bien la decisión de crear la comisión de la verdad y la reconciliación fue verdaderamente un producto de tipo local, y el apartheid fue sin lugar a dudas cruel, nos equivocaríamos al igualarlo con crímenes internacionales como el genocidio de Ruanda. La comisión de la verdad y la reconciliación de Sudáfrica recibió apoyo de la población por su negociación subyacente, la cual animaba a los delincuentes a ocultar libremente información atinente a su participación en el régimen apartheid en intercambio de una inmunidad de ser procesados penalmente. El intercambio de información facilitó las manifestaciones de remordimiento, y con ello vino la reconciliación entre los grupos relevantes. Si bien este cálculo particular funcionó, en parte por la naturaleza de la sociedad africana y los crímenes tan particulares del régimen apartheid, el hecho de que el proceso de verdad y reconciliación funcionó tan bien no es evidencia concluyente de que este proceso funcionaría en otras sociedades.

En contraste con lo anterior, los elementos claves del acercamiento a la ley criminal incluyen el arresto, el juicio público y un castigo, de lo cual se desprenden múltiples ventajas en este acercamiento que se ajustan a los beneficios de un proceso criminal durante tiempos de paz: los delincuentes son juzgados y castigados por sus crímenes, los criminales en potencia son disuadidos de cometer crímenes en el futuro y el juicio provee oportunidades para que las víctimas hagan parte de los procesos - ya sea como partes de buena fe dentro de los mismos (constituirse como parte civil), o simplemente como testigos, quienes bajo gravedad de juramento describen el maltrato que han sufrido-. Para las víctimas esto representa la capacidad de participar en un proceso penal de inmensa importancia. Finalmente, los juicios públicos tienen una alta relevancia en la justificación de mecanismos no penales: la oportunidad de establecer, registrar y preservar evidencias relacionadas con la conducta, logrando así una importante función histórica y pedagógica. En muchos casos de atrocidades en masa, no habrá registros históricos a menos que haya una corte (con fiscales y abogados de defensa), cuyo objetivo sea articular las evidencias de manera relevante y hacer público el acceso a ellas.
Para estar seguros, existen deficiencias en el acercamiento penal. Primero, las atrocidades en masa a menudo involucran miles de autores y la justicia penal puede ser incapaz de manejar esta cantidad de juicios; los fiscales deben escrutar qué criminales deben ser procesados. Segundo, no está claro si un proceso penal es apropiado, o si podría ser una oportunidad exitosa para la historiografía. En el contexto nacional, los juicios penales son diseñados con un propósito: determinar la culpabilidad o la inocencia del acusado mediante la estructuración legal y fáctica de determinaciones, de acuerdo con los procesos que protegen los intereses de ambos (ente acusador y defensa). Cuando los procesos penales buscan iniciativas globales más grandes (proporcionar compensación por el mal hecho a grupos o establecer un registro histórico), los juicios pierden su enfoque. La cantidad de víctimas y alegatos fácticos se salen de control llevando a juicios dilatados ${ }^{6}$. Así, por ejemplo, es común para los juicios en el tribunal penal internacional para la antigua Yugoslavia que estos excedan las 1000 páginas, en parte porque los juicios incluyen no solo factores relevantes a la culpabilidad y la inocencia, sino también una muestra representativa de evidencia fáctica para situar la culpabilidad del acusado dentro de un contexto más amplio.

Las cortes penales deberían enfocarse en someter el comportamiento de los acusados al escrutinio del sistema legal simplemente porque cometer delitos internacionales con impunidad constituye un mal moral adicional e independiente, más allá del mal subyacente. En este sentido, la regla antiimpunidad esta deontológicamente justificada sin tener en cuenta cualquier beneficio consecuencialista del proceso penal, ya que algunos crímenes son tan horribles que exigen castigos para los infractores. La razón para esto es muy kantiana: si los infractores se escapan a todas las consecuencias significativas por violar el deber moral de extender un trato humanitario durante la guerra, la norma en sí y el sistema legal diseñado para reivindicarlo se vuelve un cascarón vacío. Al castigar al infractor, la comunidad se reasegura en su compromiso a la racionalidad de la norma subyacente. Bajo este entendido, el proceso penal está moralmente justificado, sin tener en cuenta si se puede - de forma empírica- trazar un resultado socialmente positivo de ello.

6 Véase Timothy William Waters. The Milosevic Trial: AN Autopsy. Oxford University Press. 2013. 


\section{III. ¿CÓMO PODEMOS ALCANZAR LA}

\section{JUSTICIA DESPUÉS DE LA GUERRA?}

\section{A. Quién debe ser juzgado}

En la práctica contemporánea es común que los ideólogos y los planificadores sean juzgados en las cortes internacionales, mientras que los autores materiales no lo son. Los juicios por crímenes de guerra a menudo se enfocan en los altos mandos, quienes por lo general están lejos de la escena del crimen y deben ser conectados con los autores materiales a través de complejas doctrinas legales diseñadas para atribuir responsabilidad legal a quienes dieron las ordenes, a quienes determinaron la conducta, a quienes concertaron el delito o a quienes tuvieron control del delito a distancia?

Existen dos argumentos que deben considerarse del porqué quienes idean estas conductas son vistos como más culpables. Primero, los altos mandos controlan la ocurrencia del crimen; en la mayoría de los casos si el autor material se negara a cumplir con la orden, será inmediatamente reemplazado por alguien más dispuesto a ello. Este argumento basado en el control ha sido adoptado por algunas cortes internacionales para explicar por qué los altos mandos deben ser vistos como los autores principales (o coautores), mientras que los autores materiales deben ser tenidos como simples cómplices. El segundo argumento hace un llamado a las intenciones conjuntas y la planeación de acuerdo con el sentido que plantea Michael Bratman ${ }^{8}$. Los autores con un mayor nivel de participación tienen una intención conjunta de llevar a cabo el delito, lo cual es un proceso que inevitablemente requiere una coordinación mayor y la combinación de planes menores. Los soldados de a pie individualmente considerados, rara vez pueden ser considerados dentro de estos criterios. Mientras que los autores materiales con toda evidencia son responsables por sus propias conductas, rara vez se involucran en la planeación de alto nivel, lo cual adicionalmente los haría moralmente responsables por todo el plan criminal. Independientemente de la teoría utilizada para explicar la relación entre los planificadores y los autores materiales, está claro que los primeros son más culpables que los segundos.

\footnotetext{
7 Para un buen análisis de estas doctrinas, véase Elies Van Sliedregt. Individual CRiminal Responsibility in International LaW. Oxford University Press. 2012.

8 Cf. Michael E. Bratman. Shared intention. Eтнics 104(1). 1993. Pág. 97-113.
}

Ahora bien, para el delito de agresión, solo aquellos individuos que "estando en condiciones de controlar o dirigir efectivamente la acción política o militar de un Estado" son susceptibles de ser juzgados, si planifican, preparan, inician o realizan un acto de agresión'; así, el requisito de que haya "control", y de que este sea directo, aseguran que el soldado común no pueda ser juzgado. Si pudiesen ser juzgados los soldados comunes o ser castigados por su participación en el delito de agresión, la línea divisoria entre el jus ad bellum y el jus in bello estaría comprometida para comodidad de los revisionistas de las teorías de la guerra justa, pero esto daría un nuevo rumbo a las leyes de la guerra y su concepto neutral de la beligerancia.

¿Deben enfrentar responsabilidad penal los soldados por participar en una guerra injustificada? Esta pregunta depende de la igualdad moral de los combatientes, un problema filosófico que puede ser tratado en su totalidad aquí. Primero, incluso los revisionistas de las teorías de guerra justa que rechazan la igualdad moral de los combatientes, pueden llegar a concluir por razones instrumentales que los juzgamientos de posguerra con base en rango deben ser evitadas, ya sea porque son poco prácticas o simplemente porque juicios de posguerra podrían dificultar una reconciliación social. Al punto que los procesos de "desnazificación” o un proceso análogo es necesario, esto podría ser logrado por aproximaciones no penales. No obstante lo anterior, pongamos estas consideraciones de lado por el momento. La igualdad moral de los combatientes depende de una visión colectiva de la moralidad en la guerra; los agentes moralmente relevantes son las entidades políticas colectivas a favor de las cuales combaten los soldados. Cuando un Estado o nación lanza un ataque injustificado, es ese grupo colectivo el responsable por violar las normas morales atinentes al uso de la fuerza, ya que los líderes políticos son los que toman las decisiones relevantes, un ejército profesional - ya sea este reclutado o voluntario- es un instrumento (máquina humana) a través de la cual la política se implementa.

La igualdad moral resultante está justificada porque ella conserva la naturaleza profesional de la guerra, lo cual es el ingrediente esencial de una guerra limitada. Todas las naciones y la gente se benefician de un contexto militar en el que los soldados disfrutan de los privilegios de los combatientes a cambio de una prohibición moral de atacar directamente a los civiles. Jugando con este trato (libertad de responsabilidad penal a menos que los ciudadanos sean

9 Véase Estatuto de Roma, Artículo 8. 
intencionalmente atacados) pondrá a prueba cada pilar de una guerra limitada, convirtiéndose en últimas en una guerra total. Si los soldados se preocuparan de que podrían ser juzgados como "combatientes injustificados" al final de un conflicto armado, estos tendrán la motivación de ganar la guerra a toda costa, incluyendo con esto matar a los civiles en el proceso. El privilegio de los combatientes le da al soldado profesional una razón para actuar dentro de los límites morales de una guerra.

El trato esencial descrito arriba, el cual da a los civiles un pase libre de verse tratados como objetivos de guerra, no los hace inmunes de responsabilidades en los esfuerzos de la misma. No obstante, ellos son inmunes de un ataque, son responsables por su participación en el proceso político y social que lleva a la decisión de un Estado de lanzar una guerra injustificada. Es así que es apropiado cargar a la población civil con el peso de los preparativos para una guerra, si estos apoyaron la decisión del Estado de empezar una guerra injustificada. Además, de manera abstracta, la población civil merecidamente comparte la vergüenza colectiva asociada con el comportamiento de un Estado. El poder de estos para incoar métodos de asegurar la responsabilidad moral no debe ser subestimado. La población alemana aún lucha con la responsabilidad colectiva por el holocausto (una razón por la que Alemania ofrece una defensa tan fuerte del orden legal internacional); la frase "Nunca más" es más que una frase trillada, estructura una autoconcepción de un pueblo de manera duradera y transformadora.

\section{IV. ¿POR QUÉ CARGOS DEBEN SER JUZGADOS?}

Aun cuando la regla antiimpunidad exige responsabilidad por todas las atrocidades de la guerra, la comunidad internacional ha concluido que solo algunos delitos están sujetos a juicio ante tribunales internacionales. Mientras que las cortes nacionales deben juzgar a los individuos por homicidio como delito nacional, la maquinaria de justicia internacional solo entra en acción cuando un acusado comete un delito considerado como internacional ${ }^{10}$. Algunos estudiosos han puesto en evidencia cuan técnicos

10 Así, por ejemplo, Jhon Demjanjuk fue juzgado por complicidad en 28060 cargos de homicidio a fin de evitar preguntas incomodas atinentes al estado del Derecho penal internacional, al tiempo en que los delitos fueron cometidos. son los delitos internacionales modernos tales como la agresión, los crímenes contra la humanidad, el genocidio y los crímenes de guerra, y preferirían reemplazarlos con la definición moderna y de sentido común de "crímenes atroces"11. Este acercamiento evitaría la naturaleza ad hoc de los delitos actuales y minimizaría la posibilidad de que los crímenes caigan en las grietas de las definiciones. Por ejemplo, el genocidio requiere un ataque contra un grupo nacional, étnico, racial o religioso, pero los grupos políticos permanecen desprotegidos por la ley y un ataque contra ellos no constituye genocidio. De la misma manera, un crimen contra la humanidad requiere un ataque general o sistemático, lo cual deja por fuera las atrocidades aisladas o no planeadas. Finalmente, los crímenes de guerra tienen un nexo con los conflictos armados, de modo que excluyen las atrocidades cometidas en tiempos de paz. En consecuencia, algunas atrocidades podrían ser excluidas de estas categorías técnicas, las cuales supuestamente no tienen mayor significado normativo o jerarquía moral. Si esta visión es correcta, entonces no hace ninguna diferencia moral que un acusado sea juzgado por crímenes contra la humanidad o genocidio, o inclusive un crimen internacional (en oposición a uno nacional) de ninguna manera.

Este punto de vista está profundamente errado - como lo explicará la breve discusión que sigue-, pues los delitos internacionales base se desprenden de compromisos normativos diferentes, y cada uno presenta problemas de definición únicos que requieren una solución. Lo que los une es un contexto colectivo que es muy diferente a los crímenes nacionales. Fusionarlos en una sola noción de "crimen atroz" concede demasiado a nuestro concepto popular de matanza, sin distinciones en tiempo de guerra. Aunque la definición legal técnica no está más allá de la crítica y las reformas son a veces necesarias, la definición general es filosóficamente coherente y moralmente justificada. Tal y como lo argumentan David Luban et al., los crímenes contra la humanidad involucran matanzas indiscriminadas que a través de su comisión ponen en tela de juicio el humanismo de la comunidad mundial. Ellos, a menudo, pero no siempre, involucran crímenes cometidos por el soberano en contra de sus súbditos, una violación de una obligación fiduciaria que desencadena el derecho a una intervención judicial de tipo internacional ${ }^{12}$.

11 Véase David Scheffer. The Merits of unifying Terms: "Atrocity Crimes" and "Atrocity Law". Genocide Studies and PRevention 2. 2007. Pág. 91.

12 Véase también Larry May. Crímenes Contra LA HUMANIDAD. Cambridge University Press. 2004. Pág. 75. 
El genocidio involucra una verdadera criminalidad colectiva, la destrucción existencial o tentativa de destrucción de un grupo protegido a manos de otro ${ }^{13}$. Los crímenes de guerra involucran una violación a la prohibición básica en contra de una guerra total, a favor de una guerra limitada que excluye a los civiles, tanto como sea posible, de los terrores de esta. Esta sección pone de presente algunos problemas con la aplicación de estas categorías mientras sugiere porqué los delitos son categorías filosóficamente sobresalientes.

\section{A. Crímenes contra la humanidad}

Al ser una categoría especial, los crímenes contra la humanidad generalmente involucran una gran cantidad de muertes. Si bien a un nivel más técnico, múltiples delitos tales como el acceso carnal violento o la tortura (no solo los homicidios) encajan como crímenes contra la humanidad, ha habido múltiples intentos de dar una base para este delito, más concretamente de dar la seriedad que trae consigo este título, o sea que el delito represente una violación a la humanidad misma en vez de un simple delito en contra de las víctimas ${ }^{14}$. De ser convincente este término, ayudaría a explicar el tema de la jurisdicción que tienen los tribunales internacionales para juzgar un delito: si el crimen es contra la humanidad misma, entonces es la comunidad mundial como representantes de la humanidad quien se encuentra en la mejor posición de juzgar dicho delito.

Este punto de vista recibe apoyo en la doctrina positiva bajo el concepto de erga omnes, una obligación bajo la ley internacional que se atribuye no solo a las partes en especial, sino a todos en el mundo. El objetivo de erga omnes es limitar el alcance de la soberanía, un concepto que tradicionalmente pone una barrera alrededor de los asuntos internos de un Estado, de manera que este resulta inmune a las

13 Aquí hay un área en la que la descripción de la ley está claramente equivocada. El genocidio involucra un conflicto de grupo entre grupos enemigos, pero la definición de este delito dada por el tribunal penal internacional para Ruanda erróneamente sugiere que un individuo actuando solo (sin coautores) puede cometer un genocidio, lo cual se separa significativamente del paradigma del conflicto de un grupo contra otro grupo.

14 Por ejemplo, David Luban se concentra en su término "Humanidad", esto es, "la parte interesada" en delitos contra la humanidad. El crimen involucra no solo a las víctimas, sino a toda la comunidad mundial. Luban distingue esto del hecho de que el crimen desconoce la "humanidad" que todos compartimos, ya que estos crímenes son tan salvajes que ponen en tela de juicio la distinción entre humanos (criaturas políticas) y los salvajes. interferencias externas. En el caso de obligaciones morales bilaterales o multilaterales, una ruptura desencadena la preocupación de las partes involucradas, sin embargo, los terceros corren con menos suerte, ya que la ruptura no le proporciona a aquellos justificación para actuar o el derecho a responder, de modo que clasificar algunas obligaciones legales como Erga omnes evita este problema.

¿Qué crímenes son lo suficientemente graves que constituyen crímenes contra la humanidad misma? Bajo la doctrina actual, el requisito principal es que dicho crimen sea generalizado o sistemático y cometido en la búsqueda de un plan o política de Estado de alguna organización. En un nivel filosófico, estos requisitos son cruciales, pues que sea generalizado o sistemático asegura que dichos crímenes no sean temas aislados, aunque estrictamente hablando para ser sistemático requiere una verdadera acción colectiva, los crímenes generalizados podrían en teoría surgir de una sumatoria de acciones individuales. Sin embargo, de haber cualquier posibilidad de que una sumatoria de acciones individuales pueda clasificar, el requisito de existir un plan o política elimina dicha posibilidad.

El requisito de que exista un plan o una política requiere una justificación conceptual muy sustancial, ya que no es claro qué tipo de entidad debe desarrollar dicho plan o política. El paradigma de Núremberg permitió que las políticas organizacionales se calificaran como un crimen contra la humanidad, aunque en esa situación las organizaciones eran entidades subestatales tales como la Gestapo o las $\mathrm{ss}^{15}$. Nadie duda que las políticas que emergen de una entidad subestatal de este tipo deben y están obligadas a cumplir con el estándar de crímenes contra la humanidad. Pero, ¿qué hay de las organizaciones por fuera de la ley que no son subunidades de un gobierno de iure? En juicios recientes en la Corte Penal Internacional se alegó que las organizaciones criminales locales (por ejemplo La Mungiki) pueden clasificar como una organización relevante ${ }^{16}$. En el caso más extremo, los fiscales en la Corte Penal Internacional arguyen que una "red" sin nombre de criminales constituye dicha organización relevante ${ }^{17}$. El último ejemplo disuelve el requisito totalmente, ya que siempre será

15 Véase David Luban. A Theory of Crimes against Humanity. Yale Journal of international LaW 29. 2004. Pág. 85.

16 Véase Prosecutor vs. Francis kirimi Muthaura and Uhuru Muigai Kenyatta. Decisión sobre la Confirmación de Cargos. ICC01/09-02/11, Cámara de pre-juicio II. (Enero 23 del 2012).

17 Véase Presecutor vs. William Samoei Ruto and Joshua Arap Sang. Decisión sobre la confirmación de cargos, Caso N. ${ }^{\circ}$ ICC01/09-01/11, Cámara de Pre-Juicio II. (Enero 23 del 2012). 
posible identificar a un gran número de autores que se pueden definir como una "organización" relevante para los propósitos de un requisito de existencia de un plan o una política. Esto constituye un reductio ad absurdum. La idea detrás del crimen es el uso de estructuras políticas o sociales, la corrupción o el cáncer de la política como lo denomina Luban, al servicio de la criminalidad en masa. La idea es que una maquinaria organizada, ya sea una estructura de un Estado de iure o una fuente de poder organizacional de facto, es intervenida para la implementación de una maquinaria mortal. En consecuencia, el elemento organizacional de los crímenes contra la humanidad no solo está moralmente justificado, sino que debe ser celosamente vigilado, las tentativas de diluir o eliminar este requerimiento violan la subyacente raison d'etre $^{18}$ del delito: en la transformación de estructuras sociopolíticas en máquinas de muerte, aquella estructura debe tener una existencia independiente por sobre aquellos actos delictivos que constituyen un crimen contra la humanidad, de otra manera, el requisito organizacional desaparece totalmente. Esto distingue los crímenes contra la humanidad de la noción de sentido común de una atrocidad ${ }^{19}$.

\section{B. Genocidio}

En el contexto de genocidio, el supuesto del delito es un acto previo realizado con intención genocida, es decir, la búsqueda de la destrucción, de manera completa o en parte, a un grupo protegido ${ }^{20}$. Mucha tinta ha corrido sobre la explicación de qué constituye un grupo protegido. La convención sobre el genocidio y todas las codificaciones al respecto limitan los grupos a nacionales, étnicos, raciales o religiosos, un listado que podría ser poco incluyente desde la perspectiva de la teoría normativa ${ }^{21}$. Varias han sido las iniciativas académicas hechas a fin de incluir los grupos políticos, un requisito que incluiría atrocidades tales como las purgas de Stalin ${ }^{22}$. Sin embargo, al permitir que constituyan genocidio los ataques a los grupos políticos, las propuestas pueden llevar a una sobreinclusión como solución a la sub-inclusión de la

\footnotetext{
18 "Razón de ser".

19 La investigación no es si la conducta es criminal o no, pero qué tipo de delito ha sido cometido: es la violación nacional o internacional, y si es así, ¿debería ser descrito como un crimen contra la humanidad o algún otro delito?

20 Véase Estatuto de Roma, Artículo 6; Convención sobre el Genocidio, Articulo II.

21 Convención sobre el genocidio, Artículo II.

22 E.g. David Nersessian. Genocide and Political Groups. Oxford University Press. 2010.
}

ley vigente. Es claro que el presente esquema actual propone dificultades cuando grupos tribales o culturales no encajan dentro de los grupos protegidos, una dificultad que puede ser abordada con la inclusión de grupos políticos. Esta dificultad se hizo especialmente visible en el tribunal penal para Ruanda, el cual encontró que el ataque coordinado de las fuerzas Hutu a la minoría Tutsi en Ruanda constituía un genocidio ${ }^{23}$. Mientras que esta conclusión está apoyada por la intuición - este fue sin lugar a dudas un caso de violencia masiva de grupo contra grupo--, el tribunal penal para Ruanda, no obstante, fue forzado a hacer cambios a fin de ubicar las categorías Tutsi y Hutu como una clasificación de tipo étnica.

¿Clasificar un ataque particular como genocidio (en oposición a un "simple" crimen contra la humanidad) tiene algún significado especial de tipo moral o legal? Los tribunales internacionales modernos han rechazado firmemente el establecimiento de una jerarquía de crímenes internacionales. En otras palabras, los jueces internacionales se han rehusado a sostener que el genocidio es inherentemente un crimen contra la humanidad. ¿En ausencia de esta jerarquía, qué recompensa normativa existe o puede ser obtenida al etiquetar un ataque como genocida? A pesar de este rechazo persistente de los jueces internacionales, el genocidio representa una forma muy particular de criminalidad internacional, una que pone como objetivo a los grupos como tal, estos es, el genos de genocidio ${ }^{24}$. Por otra parte, la ley del genocidio presupone de manera correcta que estos grupos tienen un estatus moral independiente. Uno puede verlos como instrumentalmente beneficiosos, como elemento necesario para un florecimiento humano. Los seres humanos son seres políticos, situados en grupos que suministran conexiones valiosas con otros seres humanos, a través del material que suministra la cultura, el lenguaje, la tradición y la religión, entre otros artefactos sociales. Cuando le son negadas estas conexiones, los seres humanos se enfrentan a obstáculos considerables en aras de ese florecimiento.

En aplicación de esta medida, la lista de grupos protegidos por la ley del genocidio es sub-inclusiva. La pertenencia a algunos de estos grupos puede ser importante para el florecimiento humano, aunque el grupo no pueda ser descrito como uno de tipo nacional, étnico racial o religioso. Con el tiempo, la lista de grupos protegidos podría ser cuidadosamente

23 Véase Prosecutor vs. Akayesu. Caso N. ${ }^{\circ}$ ICTR-96-4-T, Camara de Juicio I. Parágrafo 702. Septiembre 2 de 1998.

24 Cf. Larry May. Genocide: A Normative Account. Cambridge University Press. 2010. 
expandida. El principio unificador detrás de esta lista es la inmutabilidad de las características de grupo bajo cuestión. Las características étnicas y raciales son las más inmutables y no pueden ser fácilmente revisadas. La identidad nacional está sujeta a revisión basada en cambios voluntarios de ciudadanía, y la identidad religiosa está sujeta a conversión. Esto dicho, la nacionalidad (de nacimiento) o la religión nunca están sujetas a revisión, y pueden ser una característica sobresaliente en campañas genocidas. La ley prioriza el grupo más inmutable de características para la protección, pero parece probable que la afiliación de tipo tribal o a un grupo político puede ser lo suficientemente inmutable para merecer protección bajo una concepción amplia del genocidio. Los miembros de grupos políticos que son objetivo de exterminación, como en las purgas de Stalin o por parte del Khmer Rouge, son víctimas de un conflicto de grupo mejor descrito con la palabra genocidio.

El genocidio representa un mal moral grave porque los grupos tienen una moral independiente que no se agota con su valor instrumental, consecuentemente, los actos que desencadenan una responsabilidad genocida incluyen actos que no necesariamente requieren asesinar a otros seres humanos; por ejemplo, implementar medidas que busquen prevenir los nacimientos o la transferencia de los niños de un grupo a otro grupo ${ }^{25}$. Estos actos pueden destruir un grupo sin que necesariamente se mate a miembros del mismo: a través de un proceso de desgaste lento el grupo se marchita al negar el ingreso a nuevos individuos. Esto solo puede ser interpretado como genocidio una vez que se concluye que el genocidio es un crimen irreductiblemente colectivo para proteger el "genos" como tal, no solo a los individuos que constituyen el grupo.

\section{Crímenes de guerra}

Los crímenes de guerra siguen siendo un delito internacional que está ligado a un conflicto armado. Si no hay guerra, no hay crimen de guerra (por definición). Este requisito desencadena tensión entre abogados de derechos humanos y los abogados penalistas internacionales, dos campos que habitualmente tienen perspectivas afines o que en ocasiones se superponen. Fiscales y jueces en tribunales internacionales están inclinados a adoptar o apoyar definiciones amplias de un conflicto armado, ya que solo con la

25 Véase la Convención sobre el Genocidio, Artículos II (d) y II (e). existencia de un conflicto armado tendrá el tribunal jurisdicción sobre las violaciones del jus in bello. Hay un sesgo incluido a favor de un punto de vista más amplio del punto de vista geográfico y temporal de un conflicto armado; en contraste, los activistas de derechos humanos tienen el impulso opuesto. Ellos desean limitar, cuanto sea posible, el privilegio de beligerancia desencadenado por el conflicto armado, y están sesgados a favor de una definición geográfica más limitada del mismo.

Los ataque terroristas no están catalogados como crímenes de guerra a menos que dicho ataque sea cometido en un conflicto armado. Esto es irónico desde que los ataques del 9/11 desencadenaron un conflicto armado entre los Estados Unidos y al-Qaeda, si bien no había un conflicto armado preexistente en ese momento - a menos que se devuelva el principio del conflicto al ataque al U.S.S. Cole en el 2000-. La alternativa es que se puede calificar a un ataque terrorista como un crimen contra la humanidad. Sin embargo, los ataques a menudo son aislados y no se ajustan a los requisitos o políticas organizacionales para ser tenidos como crímenes contra la humanidad. En respuesta, el tribunal especial para el Líbano concluyo con una decisión controversial al establecer que el terrorismo es un crimen internacional bajo la ley consuetudinaria internacional, aunque está por verse si este precedente tendrá impacto jurisprudencial ${ }^{26}$.

\section{Agresión}

Los crímenes cometidos durante un conflicto armado involucran tanto el comportamiento colectivo, como el individual. La dimensión colectiva incluye estándares básicos para el uso de la fuerza bajo el jus ad bellum, incluyendo los criterios de legítima defensa. En consecuencia, los Estados que violan la prohibición internacional en contra de la fuerza agresiva deben ser juzgados por su conducta, aunque haya actualmente muy pocos espacios institucionales en los que esto pueda ocurrir. El consejo de seguridad puede emitir una resolución vinculante condenando aquella conducta, aunque no en situaciones en las que aquella conducta tiene que ver con un miembro permanente (o inclusive un aliado cercano) del consejo que puede ejercer su derecho al veto. Los Estados afectados pueden accionar ante la Corte Internacional

26 Véase la decisión interlocutoria con respecto a la ley aplicable: Cámara de Apelaciones. Terrorismo, concierto para delinquir, homicidio, perpetración cargos acumulativos (sTL-11-01/I/AC/ R176bis). Febrero 16 del 2011. 
de Justicia (CIJ), aunque la jurisdicción entre la CIJ y el consejo de seguridad en materia de paz y seguridad tiene profundas discrepancias que permanecen sin resolver. Por otra parte, la jurisdicción de la ciJ está ampliamente basada en el consentimiento, y la posibilidad de un futuro castigo ante la corte puede llevar a un Estado a retirarse de la jurisdicción de la corte, tal y como lo hizo Estado Unidos en 1986.

Si la violación al jus ad bellum es lo suficientemente grave, puede llegar a constituir el crimen de agresión, el cual figuró de forma muy prominente en Núremberg bajo la ahora pintoresca etiqueta de "crímenes contra la paz". De hecho, los jueces en el tribunal militar internacional de Núremberg se refirieron a él como el crimen supremo internacional, ya que contenía en si el mal completo o el mal del todo, es decir, la guerra agresiva era la raíz de todos los demás crímenes internacionales. Aunque esto formó la base para el enjuiciamiento del esfuerzo de guerra Nazi, de hecho no era correcta. El Holocausto fue causado tanto por el odio genocida, como por el expansionismo agresivo; aun si los Nazis hubieran contenido dicha conducta genocida hacia los judíos que vivían dentro de Alemania, esto hubiera constituido un crimen incalificable. En las décadas siguientes, atrocidades muy serias han hecho surgir conflictos no internacionales y guerras civiles en las que las agresiones trans-fronterizas eran irrelevantes. El fraccionamiento de Yugoslavia y el genocidio de Ruanda son solo dos ejemplos obvios. Sin embargo, la noción de que un crimen enteramente interno, como las matanzas de judíos que vivían en Alemania, era un asunto de interés internacional apropiado para el enjuiciamiento ante un tribunal internacional, era la norma en el proceso en desarrollo en 1945. En consecuencia, los fiscales en Núremberg eligieron limitar sus cargos de crímenes contra la humanidad a la matanza de las juderías europeas en los territorios ocupados fuera de Alemania, territorios que fueron vencidos en conquistas ilegales cayendo así bajo el estandarte de agresión.

Desafortunadamente, Núremberg representó el último gran juicio por agresión. Cuando el Consejo de Seguridad creó los tribunales para Yugoslavia y Ruanda en 1993 y 1994, respectivamente, excluyó la jurisdicción por agresión de los estatutos vigentes. A la Corte Penal Internacional se le negó jurisdicción de agresión cuando se elaboró el Estatuto de Roma en 1998, hasta que la asamblea de Estados pudiese adoptar una definición del crimen. Ese día llegó en la convención de Kampala en el 2010, en la cual los Estados parte adoptaron una definición que se asemeja mucho a la de la asamblea general de $1974^{27}$. El acuerdo solo fue posible porque las partes adoptaron un mecanismo de activación bizantino que cuidadosamente circunscribe las condiciones bajo las cuales un caso de agresión puede ser llevado a la $\operatorname{corte}^{28}$. El fiscal de la Corte Penal Internacional puede proceder a investigar si el Consejo de Seguridad determina que el crimen de agresión ha tenido lugar. En la ausencia de dicha determinación, el fiscal debe recibir una pre-autorización de una cámara de juicios preliminares de la Corte Penal Internacional; además, puede ocurrir que se bloquee la investigación por parte del Consejo de Seguridad invocando su poder de aplazamiento ${ }^{29}$. Asimismo, los Estados parte dentro del Estatuto de Roma pueden eximirse de la jurisdicción por dicho crimen con la presentación de una declaración en el registro. Como resultado de estas enmiendas, parece ser que la agresión seguirá sin ver un juicio en el futuro.

Desde la perspectiva de la regla antiimpunidad, estos obstáculos jurisdiccionales son una carencia del sistema actual. Hay una laguna dentro de la responsabilidad por el crimen de agresión y otras violaciones menos severas del jus ad bellum. Esto dicho, las normas internacionales informales, incluyendo el rechazo y no cooperación entre futuros compañeros de tratado, puede producir un "castigo" social para aquellos Estados que se vean envueltos en actos ilícitos. Los Estados agresivos, en algunos contextos, son catalogados como naciones rebeldes y son destinatarios de las consecuencias por sus impulsos beligerantes ${ }^{30}$. De otra parte, algunos Estados pueden tener una presencia militar lo suficientemente fuerte que les permita actuar de forma agresiva sin arriesgarse a un aislamiento geopolítico. Si esto es acertado, significa que la regla antiimpunidad no ha sido completamente actualizada en la práctica del jus ad bellum.

27 Véase la resolución de la Asamblea General. 3314 (xxIx). Diciembre 14 de 1974. Disponible en http://www.un. org/es/comun/docs/?symbol=A/RES/3314(XXIX\&Lang=S\&Area $=$ RESOLUTION

28 El mecanismo de activación está codificado en el artículo 15bis y 15 del Estatuto de Roma. Para una descripción del papel de Estados Unidos durante las negociaciones, véase Beth van Schaack. Negotiating at the Interface of Power \& Law: The Crime of Aggression. Columbia Journal of Transnational Law 49. 2011. Pág. 505

29 El poder de aplazamiento, codificado en el Artículo 16 del Estatuto de Roma, permite al Consejo de Seguridad bloquear investigaciones de la CPI por un año; dicha facultad es infinitamente renovable.

30 Véase Scott J. Shapiro y Oona A. Hathaway. Outcasting: Enforcement in Domestic and International Law. YALE LAW Journal 121. 2011. Pág. 252. 


\section{V. ¿POR QUIÉNES DEBEN SER JUZGADOS?}

Ambas cortes nacionales o internacionales pueden llevar a cabo juicios por conductas criminales; cada una tiene sus ventajas. Las cortes internacionales llevan en sí la legitimidad conferida por la comunidad internacional, además de la experticia asociada a los jueces internacionales, los fiscales y los abogados de la defensa, todos ellos - al menos en teoría - tienen amplia experiencia litigando en casos por acusaciones de atrocidades en masa, en los cuales sus contrapartes nacionales pueden no tener experiencia con imputaciones por delitos en tiempo de guerra. Además de que el alcance y el tamaño de los crímenes tocan y conciernen a la comunidad global, una instancia para la imputación parecería estar justificada. Finalmente, una corte internacional puede ser más inmune a las acusaciones de parcialización o justicia para los vencedores que suelen emerger cuando una corte nacional es reunida por la parte vencedora de un conflicto armado. Es precisamente por esta razón que el Consejo de Seguridad otorgó al Tribunal Penal Internacional para la antigua Yugoslavia y al Tribunal Penal Internacional para Ruanda jurisdicción primaria que, como asunto de ley internacional, prevalece por sobre los reclamos de jurisdicción de cortes locales. Bajo este esquema, las cortes internacionales reciben la primera mordida de la manzana, determinando qué acusados son los más significativos, actúan contra ellos, y luego dejan que las cortes nacionales se encarguen de los demás.

Aunque los juicios domésticos no pueden representar - o actuar en reemplazo- de la comunidad internacional como un todo, la corte nacional puede no obstante involucrar una respuesta mucho más local cuidadosamente sintonizada y mucho más sensible con las necesidades de las víctimas. El procedimiento de la corte nacional será mucho más conocido a ambos (defensa y víctimas), además de que la corte estará localizada físicamente en el país o continente donde ocurrieron los crímenes, donde los testigos, los acusados y los abogados están localizados, en vez de en La Haya. Una comunidad destrozada por las atrocidades tiene un reclamo moral legítimo para influenciar o controlar el proceso criminal diseñado para restaurar la justicia dentro de esa comunidad ${ }^{31}$.

¿Están en posición de hacer tales juicios los sistemas locales? Esto depende del contexto particular, y

31 Algunos de estos argumentos aparecen en el artículo de Jose E. Alvarez, véase Crimes of State/Crimes of Hate: Lessons from Rwanda. Yale Journal of International Law 24. 1999. Pág. 365. es muy importante recordar que el problema tiene una bifurcación. Algunos Estados están tan maltratados por un conflicto armado que su sistema doméstico de persecución penal está muy mal preparado para manejar los requerimientos de un juicio por genocidio o por crímenes contra la humanidad. O, como ocurrió con Libia, es posible que el Estado nunca desarrolló instituciones judiciales o civiles independientes. Así, entonces, hay razones para ser escépticos sobre las habilidades de las cortes locales para entrar a juzgar. Por otra parte, los juicios pueden ayudar a desarrollar estas instituciones judiciales y el respeto por la ley que está ausente en los Estados que viven el posconflicto. Bajo este argumento, la comunidad internacional debería proporcionar apoyo intelectual y financiero para que la comunidad local aborde su propio proceso de reparación judicial, el cual hará mucho más que juzgar a los delincuentes: rehabilitará el Estado de Derecho y promoverá el respeto por las instituciones judiciales en un país donde los resultados de un conflicto dejaron dicho Estado de Derecho completamente destruido. Además, un proceso tal será sensible a las necesidades y costumbres de las partes interesadas, en vez de imponer una versión internacional de justicia que no está de acuerdo con las tradiciones locales ${ }^{32}$.

Varios de los argumentos que buscan priorizar los patrones locales de justicia son problemáticos. En algunos casos no vale la pena imitar o conservar el sistema local de justicia; hacerlo tan solo afianzaría las inequidades o debilidades existentes. Este es uno de las consecuencias de priorizar las formas locales de justicia por encima de la justicia centrada en La Haya. Bajo cualquier punto de vista, los juicios internacionales ofrecen una protección más fuerte al debido proceso, recolectan y conservan la evidencia utilizando las técnicas forenses más recientes y poseen abogados altamente calificados. La justicia local, tal y como el sistema Gacaca en Ruanda, es en ocasiones procedimentalmente deficiente y no está

32 Cabe señalar que una forma de mediación entre las demandas locales e internacionales a la justicia se debe dividir con la creación de un tribunal mixto compuesto por elementos domésticos e internacionales. Tanto las Salas Especiales de los Tribunales de Camboya (ECCC, por sus siglas en inglés) y El Tribunal especial para el Líbano (sTL, por sus siglas en inglés), son ejemplos de los tribunales mixtos. La ECCC tiene equipo de doble enjuiciamiento encabezada por un fiscal internacional y uno de Camboya co-fiscal. Es una estructura innovadora aunque algo problemática cuando los desacuerdos entre los dos fiscales llegan a un callejón sin salida. El STL fue creado para investigar y enjuiciar a los autores responsables del asesinato del exprimer ministro libanés Hariri, y tiene jurisdicción para procesar violaciones de la ley libanesa doméstica (como el asesinato). 
a tono con las necesidades de la defensa (quienes no reciben juicios justos), ni a la larga con las necesidades de la comunidad (quienes deberían tener acceso a un registro del juicio). Parecería entonces que la justicia internacional se ajusta mejor a los objetivos retributivos de un proceso penal. Sin embargo, esto es solo un poco de información para ser considerada junto con la preocupación opuesta de que la justicia centrada en La Haya tendrá una inadecuada aceptación de la población local, lo cual es un elemento esencial para la reconstrucción en el posconflicto. Por esta razón, la jurisdicción primaria para los tribunales se está desvaneciendo. El Estatuto de Roma restringe a la Corte Penal Internacional como jurisdicción complementaria, de modo que la corte solo pueda juzgar a la defensa si no existe una corte local capaz y dispuesta para juzgar a los individuos. Esto hace de la Corte Penal Internacional una corte de último recurso, diseñada para llenar el vacío cuando ninguna jurisdicción sea capaz o esté dispuesta ${ }^{33}$.

Relegar a la justicia internacional a un rol secundario, tal y como lo hace el principio de complementariedad, está mejor justificado bajo parámetros retributivos. La jurisdicción complementaria de La Corte Penal Internacional es la más clara expresión del principio de antiimpunidad, en el cual las instituciones internacionales están justificadas por la necesidad de juzgar individuos que de otra forma escaparían al castigo por su conducta. Si hay una corte local disponible para proveer una reparación legal, la jurisdicción internacional será innecesaria. En vez de apelar a la prioridad del marco legal local, la mejor justificación es que los crímenes internacionales merecen castigo y las instituciones internacionales están diseñadas para proporcionar castigo cuando no está disponible otra institución.

Aplicar el principio de complementariedad es muy controvertido en la práctica — así la Corte Penal Internacional lo ha tradicionalmente observado- si un Estado sede está dispuesto y es capaz de iniciar una investigación y juzgamiento de individuos relevantes $^{34}$. Un remedo de juicio que exonera a un individuo y nunca lo pone en aprietos es una señal de que el Estado no está dispuesto a iniciar un juicio verdadero. De la misma forma, un Estado puede no estar en capacidad de juzgar a los perpetradores de crímenes individuales si sus instituciones jurisdiccionales de tipo local son incapaces de llevar a cabo un juicio a

33 Véase Carsten Stahn y Mohamed M. El Zeidy (Eds.). The INTERNATIONAL CRIMINAL COURT AND COMPLEMENTARITY: From Theory to Practice. Cambridge University Press. 2011.

34 Vease el Estatuto de Roma, Artículo 17 gran escala, o si, como en el caso de Libia, los fiscales del gobierno no están en custodia del acusado ${ }^{35}$. Aun si el juicio se puede llevar a cabo, no está claro si el principio de complementariedad exige un resultado concreto. Si los perpetradores son imputados y sentenciados a 10 días en prisión por genocidio, ¿el castigo ligero sugiere que el principio de complementariedad fue violado? Presumiblemente, los sistemas locales tendrán estándares de castigos diferentes; lo que es una sentencia muy dura en Ruanda no será lo mismo que una sentencia dura en Noruega. El principio de complementariedad ciertamente permite la pluralidad en cuanto a castigos se refiere (desde que la complementariedad está impulsada por el respeto a acercamientos pluralistas). Por otra parte, una vez que una sentencia cae bajo un límite extremo, está claro que el acusado consiguió la impunidad "aparente" en la violación del principio anti-impunidad.

¿Es relevante si un Estado juzga a un acusado por un crimen internacional o nacional? Consideremos un Estado que juzga a un criminal de guerra por un simple homicidio de tipo nacional. ¿Podrá un juicio nacional despojar de competencia a una corte internacional bajo el principio de complementariedad? La cuestión es de etiquetas y el significado de ellas; bajo un punto de vista muy conocido, el análisis habrá de ser impulsado por los resultados, de modo que lo que importará será la duración del castigo recibido por el perpetrador en una corte nacional, y si está es más o menos comparable con la sentencia que hubiera recibido de ser acusado por un crimen internacional ante la Corte Penal Internacional ${ }^{36}$. Este estándar es normativamente convincente (porque previene un compromiso demasiado formalista de las etiquetas), aunque es muy difícil de aplicar en el mundo actual. Esto requiere un análisis de datos empíricos que no poseemos: hasta el 2014, la Corte Penal Internacional ha dictado dos condenas y una absolución. Puede ser muy difícil establecer con precisión qué sentencia

\footnotetext{
35 Este es el caso de Saif Gadafi, quien permanece bajo la custodia de los rebeldes Zintan, hecho que figuró fuertemente en la decisión de la Cámara de Cuestiones Preliminares de la CPI, ya que el gobierno central de Libia no pudo procesar a Gadafi. La Sala de Cuestiones Preliminares concluyó que a la CPI se le permitió ejercer su jurisdicción en virtud del principio de complementariedad. Véase Prosecutor vs. Gadafi. Decisión sobre la admisibilidad de la caso contra Saif Al-Islam Gaddafi, Sala de Cuestiones Preliminares I, Caso N. ${ }^{\circ}$ ICC- 01/11-01/11. (Mayo 31 del 2013).

36 Para una descripción sutil y una defensa de este punto de vista, cf. Kevin Jon Heller. A Sentence-Based Theory of Complementarity. Harvard International LaW Journal 53 2012. Pág. 202
} 
hubiese recibido el acusado de ser condenado por un crimen en la Corte Penal Internacional ${ }^{37}$.

\section{VI. ¿CÓMO DEBEN SER JUZGADOS?}

Volviendo al contexto criminal, ahora examino la forma particular que los juicios internacionales toman. Primero abordo el procedimiento que rige estos juicios, luego, en la próxima sección, la definición de las ofensas sustantivas. Aunque la mayoría de la literatura se enfoca en la definición y el contenido de los crímenes sustantivos, ahora hay un incremento en el enfoque en los procedimientos penales internacionales, y en particular en la relación entre los elementos procesales y los compromisos subyacentes de la justicia penal internacional, y como lo uno puede ser utilizado para asegurar lo otro ${ }^{38}$. Tómense, por ejemplo, tres puntos de vista en disputa en cuanto a lo procesal: participación de las víctimas, juicios in absentia y la justicia negociada.

\section{A. Participación de las víctimas}

Aunque el Tribunal Penal Internacional para Yugoslavia y el Tribunal Penal Internacional para Ruanda no incluyeron una participación formal de las víctimas, el Estatuto de Roma fue construido con las víctimas como centro del proceso. Como tal, las víctimas son parte formal del proceso, representados como grupo por un abogado, con autoridad de presentar comunicaciones de tipo oral o escrito en cuestiones de hecho y de Derecho. A partir de la sentencia de un acusado, las víctimas se hacen acreedoras a una reparación proveniente de una fiducia establecida para ellos. Aunque este sistema es muy común en el sistema de Common law, es bien conocido en la jurisdicciones del Civil law en la que la línea divisoria entre el Derecho civil y el penal no está muy definida. En algunos sistemas de Civil law las víctimas pueden iniciar una acción de tipo penal presentando un documento de tipo acusatorio ante un tribunal, y por lo tanto tiene sentido que las víctimas sean parte de un proceso ante un juzgado que tenga competencia para decidir el castigo de un acusado (si lo hay), y si hay lugar a que las víctimas reciban una

37 La Corte Penal Internacional tiene su propio centro penitenciario dentro una prisión holandesa en Scheveningen.

38 E. g. Sluiter et al. (Eds.). International Criminal Procedure: Principles and Rules. Oxford University Press. 2013 reparación de tipo civil. En contraste, la Corte Penal Internacional no le permite a las víctimas iniciar un proceso de manera directa. La estructura general de la corte es demasiado adversarial, con la fiscalía y defensa presentando sus alegatos ante un juez, y sin un juez de instrucción o de investigación (juge d'instruction) como en el sistema Francés, por ejemplo. Es más acertado describir el sistema de La Corte Penal Internacional como adversarial con elementos aislados de Civil law, incluyendo la participación de las víctimas a manera de injerto.

Al nivel filosófico, la pregunta es ¿qué justifica la participación de las víctimas? Si uno de los objetivos de la justicia internacional es crear archivo histórico, entonces la participación directa de las víctimas puede incrementar su participación en el proceso de una manera mucho más directa, en vez de ser representadas por la fiscalía. Además, las víctimas deben llegar a sentirse como partes en el proceso. Por otra parte, si los juicios internacionales están diseñados simplemente como juicios penales, es decir, con el fin de determinar la culpabilidad o la inocencia de acusados individualmente considerados y proteger sus derechos a un debido proceso, entonces la participación de las víctimas puede distraer a la corte de ese propósito. Ciertamente, el lento paso de la justicia en la Corte Penal Internacional podría ser mejorado si el proceso de juicio preliminar y el juicio fuera acelerado; remover a las víctimas de este proceso podría ser una forma de lograr dicho objetivo.

\section{B. Juicios in absentia}

¿Deben los tribunales internacionales tener bajo su custodia al acusado previo al inicio del juicio? Desde Núremberg, la tendencia ha desfavorecido los juicios in absentia (lo cual es consistente con el acercamiento del Common law en general). Este supuesto parte de la base de que un juicio justo es imposible sin la participación personal del acusado. Sin embargo, el reciente Tribunal Especial para el Líbano tiene la competencia para llevar a cabo juicios in absentia, una regla conferida a dicha corte porque las Naciones Unidas anticiparon que dicho tribunal tendría dificultades para recibir la custodia de los acusados. El asunto ha sido debatido, en un contexto diferente, en la Corte Penal Internacional, la cual no tiene competencia para proceder in absentia. Sin embargo, varios políticos de alto rango en Kenia, juzgados por crímenes contra la humanidad, solicitaron permiso para permanecer en Kenia (atendiendo asuntos de Estado), mientras que los abogados los representan 
en La Haya. Aunque la cámara de asuntos previos inicialmente rechazó estos argumentos, la asamblea de Estados después enmendó las reglas de procedimiento y de pruebas para permitir, de forma limitada, tales ausencias ${ }^{39}$.

$¿$ Los principios subyacentes de la justicia internacional aprueban los juicios in absentia? Si el objetivo del juicio es puramente didáctico o histórico, es decir, la corte se está dirigiendo a un público mucho más amplio, entonces podría haber lugar para juicios in absentia. Nunca debe olvidarse que la justificación legal (en oposición a la justificación filosófica) para crear el Tribunal Penal Internacional para la antigua Yugoslavia, el Tribunal Penal Internacional para Ruanda y el Tribunal Espacial para el Líbano era que su trabajo podría ayudar a restaurar la paz y la seguridad internacional: de modo que podría argumentarse que los juicios in absentia son mejores (bajo este entendido) que ningún juicio ${ }^{40}$. Por otra parte, una concepción más modesta de los juicios internacionales como de naturaleza puramente penal, diseñados solo para proteger el derecho a la defensa del acusado, aconsejará más cuidado antes de permitir juicios in absentia. Es difícil proteger los derechos de la defensa cuando ellos no están presentes para el juicio (aun si su ausencia es autoimpuesta).

\section{Acuerdos con la fiscalía y justicia negociada}

Finalmente, ¿deberían los juicios internacionales permitir (o alentar) acuerdos con la fiscalía? Al nivel de la administración penal, los acuerdos con la fiscalía tienen beneficios: reducen las cargas de casos, incrementan los recursos para juicios que son llevados hasta un fallo y permiten a las partes reducir los riesgos (un beneficio para fiscales y acusados por igual). Con los acuerdos, los tribunales pueden prescindir de casos no impugnados y alentar a la defensa de declararse culpables a cambio de colaborar en contra de acusados de nivel superior, cuyos casos serán llevados hasta un fallo. Por otra parte, los acuerdos pueden frustrar los objetivos primordiales de lo que

39 Véase Reglamento de Procedimiento y Prueba la CPI. Artículo 134bis. No está claro si esta regla procesal es consistente con el lenguaje del Estatuto de Roma, el cual requiere de la presencia del acusado.

40 Estos tribunales fueron creados por el Consejo de Seguridad de las Naciones Unidas en virtud de su autoridad de la Carta de la ONU, Capítulo viI, para restablecer la paz y la seguridad internacionales. Si esta disposición legal se toma en serio como idea filosófica, sugiere una justificación consecuencialista basada en la promesa o la anticipación de que la creación del tribunal producirá beneficios sociales netos para la sociedad global. se busca, como construir un registro histórico y darles a las víctimas una oportunidad de participar en el proceso. Ninguno de estos objetivos será logrado si los acusados toman un atajo y se saltan la etapa de hallazgo de hechos atado a los poderes investigativos de naturaleza coercitivos de la corte. Esto muestra la conexión íntima entre la especificidad del régimen procedimental y el fundamento normativo de lo que se busca lograr. Si el objetivo es proteger a los acusados de un castigo injusto, entonces un grupo de procedimientos está justificado; si el objetivo es dar cabida a los intereses más amplios de colectividades más grandes, entonces los procedimientos relevantes serán diferentes.

En este orden de ideas, es importante contrastar dos argumentos sobre el procedimiento penal internacional. Atrás se discutió la tensión entre las justificaciones instrumentales y deontológicas para el Derecho penal internacional (generalmente la misma tensión reaparece en el dominio del procedimiento internacional). Así, el primer punto de vista es totalmente instrumental: ¿podrá el procedimiento en cuestión sobrepasar los objetivos más amplios de la justicia penal internacional? Si el procedimiento promueve la eficiente administración de la justicia penal o promueve la causa histórica (dependiendo del objetivo correcto) entonces será justificado el procedimiento. Este procedimiento consecuencialista de procedimiento penal requiere una cuenta preexistente de los resultados relevantes para que estos sean maximizados. Pero inclusive con el desacuerdo de cuáles resultados deben ser maximizados, las diferentes posiciones comparten un marco consecuencialista común con atención al procedimiento. Esta es una manera común de entender dicho procedimiento: no tiene un valor inherente, tan solo un valor en la medida en que ayude a obtener otros resultados.

Dicho esto, los fundamentos deontológicos del procedimiento penal internacional son a menudo y de manera injusta ignorados. El procedimiento penal tiene unvalor moralinherente que no está enteramente reducido a sus consecuencias ${ }^{41}$. Bajo ese entendido, el juicio penaly sus mecanismos procedimentales representan un bien a priori siempre y cuando constituya un proceso de tipo penal de acuerdo al mandato de la ley. Esta defensa del mandato de la ley representa un bien a priori, no porque tiene beneficios para la sociedad, sino porque las atrocidades en masa se cometen en periodos de ausencia de la ley. En estos momentos,

41 Véase Jens David Ohlin. A Meta-Theory of International Criminal Procedure: Vindicating the Rule of Law. UCLA JOURNAL OF International LaW and Foreign Affairs 14. (2009). Pág. 77. 
la ley está ausente tanto de forma sustantiva como procedimental, lo cual permite que las víctimas sean sometidas a una violencia indescriptible, además de su sometimiento a los caprichos de los perpetradores. Sujetar esta conducta a los requerimientos de la ley, a través de un procedimiento penal, trae consigo evidentes beneficios para la sociedad. Pero la defensa del mandato de la ley, representado en los juicios penal posatrocidades, tiene una valía moral subyacente que no es posible reducir a aquellas consecuencias positivas que emanarían de ella. La anarquía representa una transgresión a la dignidad humana, además a la noción de que los seres humanos están sujetos a constreñimientos de tipo normativo de su conducta. Los juicios posatrocidades representan un retorno a la ley $\mathrm{y}$ al orden porque ellos imponen un escrutinio legal y moral a las conductas desplegadas en la época sin ley. De esta manera, los juicios posatrocidades conviertes periodos de anarquía en periodos gobernados por la legalidad, y en ello se defiende nuestra dignidad humana colectiva.

\section{VII. ¿CÓMO DEBEN SER CASTIGADOS LOS CULPABLES?}

Finalmente, la justicia después de la guerra requiere castigos a nivel colectivo e individual. Al nivel colectivo, los Estados que cometen ilícitos de tipo internacional deben ser castigados; sin embargo, la culpabilidad y el castigo son términos muy desconocidos en el Derecho internacional moderno. ${ }^{42}$ Las opciones de castigo incluyen reparaciones posguerra a favor de los Estados víctimas, pérdida de privilegios y posiciones dentro de organizaciones internacionales, y una pérdida de posición dentro de la comunidad internacional que podría tener consecuencias negativas en otros dominios de tipo diplomático ${ }^{43}$. A nivel individual, la justicia exige castigos para aquellos que ejecutan acciones criminales, aunque las exigencias traen consigo que solo los individuos más culpables (a nivel de planeación) serán castigados (ya sea en un tribunal nacional o uno internacional), mientras que aquellos que participaron de ofensas de tipo aislado escapan al castigo.

42 Cf. Gabriella Blum. The Crime and Punishment of States. Yale Journal of International Law. 2013. Pág. 58. ”Desde la Primera Guerra Mundial, sin embargo, la retórica moral dentro de un Estado de 'crimen y castigo' ha sido escindida del léxico del Derecho internacional".

43 Véase Shapiro y Hathaway, supra, nota 30. Pág. 258.
En términos de justificación filosófica, los castigos individuales para crímenes internacionales hacen surgir las mismas tensiones entre sistemas de tipo retributivo y consecuencialista, tal como se encuentra en la literatura del castigo en un contexto penal común. Sin embargo, hay algunas características muy singulares para el castigo de las atrocidades que son muy propias al contexto internacional ${ }^{44}$. En la literatura nacional, ya existe un debate de tipo empírico muy activo con respecto a la eficacia de la disuasión, ya sea para la pena de muerte o la cárcel. En el contexto internacional, parece claro que la disuasión (ya sea de tipo específico o general) es especialmente poco apta como una justificación para castigar. Los individuos inclinados a cometer crímenes contra la humanidad o genocidio a menudo son motivados por un odio intenso o la intolerancia, lo cual desafía los cálculos racionales; la posibilidad de un castigo futuro en La Haya puede no servir como mecanismo confiable para la alteración de decisiones. Más aún, la fealdad de la guerra puede hacer parecer a La Haya (con sus cómodas cárceles) un premio más que un castigo. Con esto dicho, los jueces en los tribunales internacionales ocasionalmente vienen de jurisdicciones nacionales en las que los castigos son muy leves en comparación a los Estados Unidos o África, y el objetivo es simplemente incapacitar a un peligroso delincuente hasta que este pueda ser rehabilitado con programas educativos y reintegrado a la sociedad (un proceso financiado con recursos estatales muy abundantes). Pero aún no está claro si este paradigma de la incapacitación y rehabilitación es adecuado para los demagogos ideológicos juzgados en un contexto de jus post bellum.

Esto deja el retribucionismo y el expresivismo como las justificaciones más apropiadas para un castigo de posguerra ${ }^{45}$. El retribucionismo, por su parte, parece particularmente apto dentro del contexto de la posguerra: si alguien "merece" un castigo es el genocida. Sin embargo, la retribución por las atrocidades de guerra padece de la misma debilidad conceptual que la retribución desde el ámbito local: localizar la conexión teórica exacta entre un desierto de tipo moral y la privación/sufrimiento. ¿Forzará el sufrimiento a un criminal a deshacerse de todas

44 Para una discusión mas amplia, véase Mark Drumbl. Atrocity, Punishment, and International Law. Cambridge University Press. 2007.

45 Hay una discusión especialmente fuerte sobre el expresivismo en Drumbl, véase también Robert D. Sloane. The Expressive Capacity of International Punishment: The Limits of the National Law Analogy and the Potential of International Criminal Law. Stanford Journal of International Law 43. 2007. Pág. 39. 
sus ventajas ilegalmente obtenidas? ¿Esto reparará el entramado moral de la sociedad? ¿Preservará la dignidad del criminal si se le trata a él o a ella como un agente responsable y racional? Hay una delgada línea entre retribucionismo y expresivismo. En el expresivismo, el castigo está diseñado para expresar el oprobio de la comunidad mundial como un elemento que podría, en teoría, ser interiorizado como uno de los componentes de la teoría retributiva. En este aspecto, el castigo sirve como un aspecto a la vez práctico y simbólico, diseñado para comunicar la determinación mundial de que los actos ejecutados son en verdad reprochables. Esto encaja con el principio subyacente de las ofensas sustantivas, en especial los crímenes en contra de la humanidad. Esto en razón a que la parte verdaderamente interesada es la comunidad mundial. De acuerdo con este principio, la comunidad reclama su compromiso con la humanidad etiquetando correctamente la conducta como un crimen contra la humanidad y adjuntándole la pena apropiada.

Los problemas con la gravedad y la proporcionalidad en los márgenes permanecen y son difíciles de resolver. La mayoría de las teorías del castigo requieren de forma acertada alguna forma de proporcionalidad, ya sea entre quienes ejecutan la conducta, o bien entre el castigo y la conducta. Bajo el primer principio, los acusados en situaciones similares deberían recibir penas similares, mientras que los acusados más culpables deberían recibir penas más prolongadas. Este marco presenta problemas, sin embargo, dada la magnitud de los delitos internacionales y la necesidad de reservar un espacio en la cima de la escala de los castigos para aquellos que han cometido las peores ofensas. Si reservamos en la cima un lugar para personas como Hitler, Milosevic o Karadzic, entonces la pena a los delincuentes menos culpables (pero aun tremendamente responsables) debe ser rebajada para mantener la proporcionalidad. El algún punto, los delincuentes en la parte baja de esta escala están recibiendo sentencias insignificantes a cambio de delitos muy serios, un resultado contra intuitivo que demanda un remedio conceptual. La respuesta correcta es exigir que el castigo refleje la gravedad inherente de la ofensa tanto como sea posible, y desechar la noción de que los castigos "siempre" reflejan diferencias relativas en cuanto a la culpabilidad. Esto es la representación de una teoría del castigo en los márgenes extremos: algunos crímenes son tan severos que se debe dar el mismo castigo (tal vez cadena perpetua) a aquellos en la cima de la culpabilidad y aquellos en la penúltima posición de la escala.

\section{CONCLUSIONES}

El retrato de este capítulo de justicia después de la guerra esta deliberadamente enfocado en el Derecho penal. Aunque hay muchos mecanismos legales y morales para alcanzar la justicia en abstracto, los juicios criminales son la mejor esperanza a la hora de respetar la norma antiimpunidad. Por la naturaleza de su conducta, los perpetradores de crímenes internacionales merecen castigos implementados dentro de un Estado de Derecho. Este capítulo ha resaltado la manera en que estos juicios deben ser conducidos: la naturaleza y la ubicación de las cortes, sus procedimientos, las ofensas sustantivas y la forma en que deben ser sentenciados. La expansión vigorosa y la institucionalización del enjuiciamiento de posconflicto en los últimos veinte años debería ser pregonada y acelerada.

\section{REFERENCIAS}

Beth van Schaack. Negotiating at the Interface of Power \& Law: The Crime of Aggression. Columbia Journal of Transnational LaW 49. 2011.

Cámara de Apelaciones. Terrorismo, concierto para delinquir, homicidio, perpetración cargos acumulativos (sTL-11-01/I/AC/R176bis). Febrero 16 del 2011.

Carsten Stahn y Mohamed M. El Zeidy (Eds.). The InTERnAtional Criminal Court and Complementarity: From Theory to Practice. Cambridge University Press. 2011

David Nersessian. Genocide and Political Groups. Oxford University Press. 2010.

David Scheffer. The Merits of unifying Terms: "Atrocity Crimes" and "Atrocity Law". Genocide Studies AND PREVENTION 2. 2007. Pág 91.

David Wippman. Atrocities, deterrence, and limits of international justice. FORDHAM INTERNATIONAL LAW JOURNAL 23. 1999.

Elies Van Sliedregt. Individual Criminal ResponsibiliTY IN International LaW. Oxford University Press. 2012.

Gabriella Blum. The Crime and Punishment of States. YAle JOURNAL OF INTERNATIONAL LAW. 2013.

Jens David Ohlin. A Meta-Theory of International Criminal Procedure: Vindicating the Rule of Law. UCLA JouRnAL of International Law and Foreign Affairs 14. (2009). 
José E. Alvarez. Crimes of State/Crimes of Hate: Lessons from Rwanda. Yale Journal of International LaW 24. 1999.

Julian Ku y Nzelibe. Do Criminal Tribunals Deter or Exacerbate Humanitarian Atrocities? WASHINGTON UNIVERSITY LAW QUARTERLY 84. 2007.

Larry May. Crímenes Contra la HumANidad. 2004. Cambridge University Press.

Larry May. Genocide: A Normative Account. Cambridge University Press. 2010.

Mark Drumbl. Atrocity, Punishment, And InternatioNAL Law. Cambridge University Press. 2007.

Max Pensky. Amnesty on Trial: Impunity, Accountability and the Norms of International Law. ETHICs \& Global PoLITICS 1. 2008.

Prosecutor vs. Akayesu. Caso N. ${ }^{\circ}$ ICTR-96-4-T, Cámara de Juicio I. Parágrafo 702. Septiembre 2 de 1998.

Prosecutor vs. Francis kirimi Muthaura and Uhuru Muigai Kenyatta. Decisión sobre la Confirmación de Cargos. ICC-01/09-02/11, Cámara de pre-juicio II. (Enero 23 del 2012).

Prosecutor vs. William Samoei Ruto and Joshua Arap Sang. Decisión sobre la confirmación de cargos, Caso $\mathrm{N}$. ICC-01/09-01/11, Cámara de Pre-Juicio II. (Enero 23 del 2012).
Prosecutor vs. Gadafi. Decisión sobre la admisibilidad de la caso contra Saif Al-Islam Gaddafi, Sala de Cuestiones Preliminares I, Caso N. ${ }^{\circ}$ ICC-01/11-01/11. Mayo 31 del 2013).

Robert D. Sloane. The Expressive Capacity of International Punishment: The Limits of the National Law Analogy and the Potential of International Criminal Law. STANFORD JOURNAL OF INTERNATIONAL LAW 43. 2007.

Scott J. Shapiro y Oona A. Hathaway. Outcasting: Enforcement in Domestic and International Law. YAle LaW JOURNAL 121. 2011.

Shahram Dana. The limits of judicial idealism: should the international criminal court engage consequentialist aspirations? PENN STATE JOURNAL OF LAW \& INTERNATiONAl AfFairs 3. 2014.

Goran Sluiter et al. (Eds.). International Criminal ProCedure: Principles and Rules. Oxford University Press. 2013.

Timothy William Waters. The Milosevic Trial: An AuTOPsy. Oxford University Press. 2013. 